\title{
Elevated levels of IL-17A and IL-35 in plasma and bronchoalveolar lavage fluid are associated with checkpoint inhibitor pneumonitis in patients with non-small cell lung cancer
}

\author{
YI NA WANG ${ }^{1}$, DAN FENG LOU ${ }^{2}$, DAN YANG LI $^{3}$, WEI JIANG ${ }^{1}$, JING YIN DONG ${ }^{4}$, \\ WEI GAO ${ }^{4}$ and $\mathrm{HONG}$ CHAO $\mathrm{CHEN}^{5}$
}

\begin{abstract}
${ }^{1}$ Department of Medical Oncology, The First Affiliated Hospital, Zhejiang University School of Medicine, Hangzhou, Zhejiang 310003; ${ }^{2}$ Department of Infectious Diseases, Shulan (Hangzhou) Hospital, Hangzhou, Zhejiang 310000;

${ }^{3}$ Department of Intensive Care Unit, The Second Affiliated Hospital, Zhejiang University School of Medicine, Hangzhou, Zhejiang 310009; ${ }^{4}$ Department of Clinical Medicine, School of Medicine, Zhejiang University City College, Hangzhou, Zhejiang 310015 ; ${ }^{5}$ Department of Clinical Laboratory, The First Affiliated Hospital, Zhejiang University School of Medicine, Hangzhou, Zhejiang 310003, P.R. China
\end{abstract}

Received July 23, 2019; Accepted April 1, 2020

DOI: $10.3892 / 01.2020 .11618$

\begin{abstract}
Advances in the immunology have identified that interleukin (IL)-17 and IL-35 are cytokines with diverse functions, serving important roles in autoimmune diseases and chronic inflammation. Checkpoint inhibitor pneumonitis (CIP) is focal or diffuse lung inflammation induced by immune checkpoint inhibitors and the underlying pathogenesis has not been fully explored. The aim of the present study was to investigate the roles of IL-17A and IL-35, and the correlation between their levels and different $\mathrm{T}$ cell subsets in CIP. The levels of IL-17A and IL-35 in peripheral blood and bronchoalveolar lavage fluid (BALF) were measured in patients with non-small cell lung cancer (NSCLC) with CIP, and the corresponding controls. The percentages of helper $\mathrm{T}$ lymphocyte (Th)1, Th2 and Th17 cells, and regulatory T cells (Tregs) in the peripheral blood were synchronically detected. Serum levels of IL-17A and IL-35 were significantly increased at the time of CIP diagnosis compared with the baseline, and significantly decreased upon clinical recovery or improvement. IL-17A and IL-35 were also increased in the BALF
\end{abstract}

Correspondence to: Dr Hong Chao Chen, Department of Clinical Laboratory, The First Affiliated Hospital, Zhejiang University School of Medicine, 79 Qing Chun Road, Hangzhou, Zhejiang 310003, P.R. China

E-mail:1505015@zju.edu.cn

Abbreviations: BALF, bronchoalveolar lavage fluid; CIP, checkpoint inhibitor pneumonitis; CT, computed tomography; IL, interleukin; IFN, interferon; irAEs, immune-related adverse events; NSCLC, non-small cell lung cancer; PD-1, programmed death receptor 1; PD-L1, programmed death receptor ligand 1; Th, helper $\mathrm{T}$ lymphocyte; Tregs, regulatory $\mathrm{T}$ cells

Key words: IL-17, IL-35, CIP, NSCLC, immunotherapy during the development of CIP compared with the baseline. Serum levels of IL-17A were positively correlated with the percentages of Th1 and Th17 cells as well as the ratio of Th17 to Tregs, but negatively associated with the frequency of Tregs in CIP. Serum levels of IL-35 were positively correlated with the percentages of Th1 and Tregs, and with the ratio of Th1 to Th2 cells in CIP. A higher frequency of Th1 and Th17 cells, as well as higher ratios of Th17 to Tregs and Th1 to Th2 cells were detected upon development of CIP comparing with the baseline. These data suggested that the activation of Th1 and Th17 cells, as well as Treg inhibition contributed to the imbalanced ratios of Th1 to Th2 and Th17 to Tregs, which resulted in increased secretion of IL-17A and IL-35 in the plasma and BALF; this may present a valuable index to monitor the development and severity of CIP in patients with NSCLC receiving immunotherapy.

\section{Introduction}

Anti-programmed death 1 (PD-1)/anti-programmed death 1 ligand 1 (PD-L1) antibodies pembrolizumab, nivolumab and atezolizumab are becoming promising new treatment options for a broad range of refractory malignancies; this has resulted in their approval by the US Food and Drug Administration for the treatment of $>14$ different types of cancer, including non-small cell lung cancer (NSCLC) (1), malignant melanoma (2), renal cell carcinoma (3), Hodgkin's lymphoma (4) and bladder cancer (5).

However, despite encouraging clinical effects, PD-1/PD-L1-targeting agents have also been associated with a spectrum of immune-related adverse events (irAEs), including skin rashes, neurotoxicity, myocarditis, colitis, hepatitis, endocrine dysfunction and pneumonitis (6). Among these irAEs, pneumonitis is rare, but potentially life-threatening. Immune-mediated pneumonitis, also termed checkpoint inhibitor pneumonitis (CIP), was initially described in a phase I trial of nivolumab in patients with different malignancies, in 
which three (2\%) patients died of severe pneumonitis (7). CIP is defined as the development of dyspnea and/or other respiratory symptoms (including cough and hypoxia) in the presence of new pulmonary infiltrates on chest imaging and in the absence of new infection (8). To date, CIP has been reported in $\leq 5 \%$ of patients in clinical trials, and the rates of grade $3 / 4$ pneumonitis are similar across tumor types. However, due to pneumonitis, patients with NSCLC appear to exhibit a higher treatment-related mortality rate (9-16). The real-world incidence of CIP may be even higher, especially as immune checkpoint inhibitors (ICIs) are currently being widely used in non-clinical trial settings. Thus, the occurrence of CIP in NSCLC has become regarded as an area of special interest.

To date, the molecular mechanism of CIP has not been fully elucidated. Current hypotheses suggest a dysregulated interaction between effector and regulatory $\mathrm{T}$ cells (Tregs) in the pulmonary interstitium, ultimately leading to an inflammatory response (17). In 2013, Barjaktarevic et al (18) revealed an organizing pneumonia pattern in patients with pneumonitis caused by an anti-cytotoxic T lymphocyte-associated antigen-4 antibody. Naidoo et al (19) examined tissue samples from 11 patients treated with anti-PD-1/PD-L1 therapy at the Memorial Sloan Kettering Cancer Center, and found that interstitial fibrosis (4/11) and organizing pneumonia (3/11) were the most common pathological manifestations. Despite the aforementioned studies, a considerable lack of data has been reported in regard to the etiology of CIP. Rapid clinical improvement upon administration of corticosteroids indicates an immune-mediated mechanism, and suggests that $\mathrm{T}$ cells may serve an important role in the pathogenesis of CIP.

Interleukin (IL)-17 is an important cytokine for regulating immune homeostasis, and the aberrant expression of IL-17 has been suggested to contribute to a number of pathologies, including asthma, pneumonitis and the generation or exacerbation of pulmonary fibrosis (20). IL-35, a recently identified heterodimeric cytokine, has been implicated to serve a crucial role in several immune-associated diseases, such as autoimmune diseases and viral infections, as well as in tumors (21). Higher levels of serum IL-35 are reportedly associated with pulmonary fibrosis (22). Thus, the present study aimed to dynamically determine the alterations in the expression levels of IL-17A and IL-35 in the peripheral blood and bronchoalveolar lavage fluid (BALF) of patients with NSCLC-related CIP, as well as to synchronically detect different subsets of $\mathrm{T}$ cells, including helper $\mathrm{T}$ lymphocytes (Th)1, Th2 and Th17 cells, and $\mathrm{CD}^{+}{ }^{+} \mathrm{CD} 25^{+}$forkhead box P3 (Foxp3) ${ }^{+}$Tregs, in the peripheral blood.

\section{Materials and methods}

Patients. Blood specimens from 13 patients with NSCLC diagnosed with CIP who received anti-PD-1/PD-L1 therapy between July 2016 and December 2018 at the Department of Medical Oncology, The First Affiliated Hospital of Zhejiang University (Hangzhou, China), were collected within 2 weeks of immuno-oncology (IO) treatment, prior to every two cycles of immunotherapy and upon onset of CIP. A total of 9 patients underwent bronchoscopy and BALF was collected at baseline and upon CIP diagnosis during bronchoscopy examination; 20 patients with locally advanced/metastatic NSCLC with available constitutive blood samples during anti-PD-1/PD-L1 treatment were included as controls, and 10 of them received bronchoscopy examination both pre- (no more than 10 days before treatment) and post-ICI treatment (after 2-5 cycles of ICI treatment). BALF was collected from the middle lobe in control patients and a newly infiltrated area in patients with CIP during bronchoscopy. The present study was a planned analysis with a prospective observational protocol approved by the Ethical Committee of The First Affiliated Hospital of Zhejiang University. Written informed consent was obtained from all subjects.

Radiological and clinical assessment. A chest computed tomography (CT) scan was mandatory for all patients at baseline, during therapy, at follow-up and upon clinical suspicion of CIP. According to the American Thoracic Society/European Respiratory Society 2002 classification $(23,24)$, the occurrence of new and diffuse lung parenchymal abnormalities on CT scans, such as ground-glass opacities, consolidations, interlobular septal thickening and intralobular lines, micronodules, bronchiectasis and architectural distortion, may correlate with drug-induced interstitial pneumonitis.

The diagnosis of CIP was based on radiological data and clinical symptoms following the guidelines of the European Society for Medical Oncology, the Society for Immunotherapy of Cancer, and the American Society for Clinical Oncology/National Comprehensive Cancer Network, which include the use of imaging (chest X-ray and/or CT), pulse oximetry and an infectious work-up (including nasal swab, sputum, blood and urine cultures) (25-28). Patients were only diagnosed with CIP after the exclusion of other causes of pulmonary disorders, such as pulmonary infection, progression of lung cancer or radiation pneumonitis based on a multidisciplinary discussion between radiologists, oncologists, pulmonologists and infectious disease specialists, although the diagnostic criteria of CIP was inconsistent. CIP severity (G1-G5) was defined according to the Common Terminology Criteria for Adverse Events, version 4.0 (29).

Detection of IL-17A and IL-35 in serum or BALF by ELISA. Peripheral blood and BALF samples were collected from patients and stored at $-80^{\circ} \mathrm{C}$ for subsequent experimentation; the samples were analyzed within 90 days of collection. The concentrations of IL-35 and IL-17A in patients with CIP and controls were quantified using cytokine-specific ELISA kits (cat. no. DY6456 for IL-35 and D1700 for IL-17A; R\&D Systems, Inc.) according to the manufacturer's protocols. Briefly, $100 \mu 1$ serum or BALF was added to microplate strips and incubated at room temperature for 2-3 h. After a total of three washes, primary antibodies for IL-35 or IL-17A were added and incubated for $1 \mathrm{~h}$ at room temperature. The wash step was then repeated. Finally, after incubation at room temperature with substrate solution for $30 \mathrm{~min}$, stop solution (acid stop solution provided with IL-17A kit and $2 \mathrm{NH}_{2} \mathrm{SO}_{4}$ with IL-35 kit (both R\&D Systems, Inc.) was added and the colorimetric density of each well was determined at a wavelength of $450 \mathrm{~nm}$ using a Multimode Reader (Tecan Infinite $\left.^{\mathrm{TM}} \mathrm{F} 200\right)$. All samples were assayed in triplicate.

Flow cytometric detection of T-cell subsets. The frequencies of different T-cell subsets in 13 patients with CIP and 20 control 
subjects were detected by flow cytometry within 2 weeks prior to IO treatment, at every two cycles of immunotherapy and at the onset of CIP. Peripheral blood mononuclear cells (PBMCs) were isolated from fresh heparinized blood by standard Ficoll-Hypaque density centrifugation (Biochrom, Ltd.) at room temperature and $670 \mathrm{xg}$ for $30 \mathrm{~min}$. PBMC isolation was performed $\leq 2 \mathrm{~h}$ after peripheral blood collection. To exclude non-specific binding, isotype-matched antibodies (mouse IgG1 monoclonal $\kappa$ antibody, cat. no. 554679, $1 \mu \mathrm{l} / 1$ million cells, BD Biosciences) were used as controls; $\geq 2 \times 10^{5}$ cells were analyzed using a FC500 MPL flow cytometer and CXP-analysis version 2.2 (both Beckman Coulter, Inc.). For Treg analysis, cell surface staining was performed with fluorescein isothiocyanate (FITC)-conjugated anti-CD25 (cat. no. 560990, $20 \mu \mathrm{l} / 1$ million cells, BD Biosciences), phycoerythrin (PE)-conjugated anti-Foxp3 (cat. no. 560046, $20 \mu \mathrm{l} / 1$ million cells, BD Biosciences), PE-cy5-conjugated anti-CD4 (cat. no. 555348, $20 \mu \mathrm{l} / 1$ million cells, BD Biosciences) or the appropriate isotype controls (mouse IgG1 monoclonal $\kappa$ antibody, cat. no. 554679, $1 \mu \mathrm{l} / 1$ million cells, BD Biosciences). The cells were incubated with the antibodies for $20 \mathrm{~min}$ at room temperature in the dark, followed by washing in PBS and subsequent flow cytometric analysis. For cytotoxic and helper T-cell subsets, the cells were incubated with PE-conjugated anti-CD3 (cat. no. 555333, $20 \mu \mathrm{l} / 1$ million cells, BD Biosciences) and PE-cy5-conjugated anti-CD4/CD8 (cat. no. 555348, $20 \mu \mathrm{l} / 1$ million cells for CD4 and cat. no. 557750, $5 \mu \mathrm{l} / 1$ million cells for CD8, both BD Biosciences) at $4^{\circ} \mathrm{C}$ for $15 \mathrm{~min}$, fixed at $4^{\circ} \mathrm{C}$ for $10 \mathrm{~min}$ using fixation buffer (cat. no. 554714, BD Biosciences) and permeabilized at room temperature for 15 min using permeabilization wash buffer (cat. no. 554714, BD Biosciences). The cells were then stained with FITC-conjugated anti-interferon- $\gamma$ (IFN- $\gamma$, cat. no. 554551, $1 \mu \mathrm{l} / 1$ million cells, BD Biosciences) or anti-IL-4 antibodies (cat. no. 559333, $20 \mu \mathrm{l} / 1$ million cells, BD Biosciences) at room temperature for $30 \mathrm{~min}$ and assessed by flow cytometry using the FC500 MPX flow cytometer with MXP software version 2.2 (Beckman Coulter, Inc.). The frequencies of Tregs $\left(\mathrm{CD} 4^{+} \mathrm{CD} 25^{+} \mathrm{Foxp} 3^{+}\right)$, and Th1 $\left(\mathrm{CD}^{+}{ }^{+} \mathrm{CD} 8-\mathrm{IFN}-\gamma^{+}\right)$and $\mathrm{Th} 2\left(\mathrm{CD}^{+} \mathrm{CD} 8-\mathrm{IL}-4^{+}\right)$cells were expressed as a percentage of the $\mathrm{CD} 4^{+} \mathrm{T}$-cell population by sequential gating on lymphocytes and $\mathrm{CD} 4^{+} \mathrm{T}$ cells.

Statistical analysis. The data were analyzed using SPSS software version 22 (IBM Corp). Categorical data are summarized as counts and percentages, and quantitative data are expressed as the mean \pm standard deviation or the median and quartile range according to their distribution. The $\chi^{2}$ test was used to analyze the baseline data of patients with NSCLC. The differences between multiple groups were determined using Kruskal-Wallis with Dunn's multiple comparisons test. The association between measures was analyzed by Pearson's correlation with Bonferroni's correction. $\mathrm{P}<0.05$ (two-tailed) was considered to indicate a statistically significant difference.

\section{Results}

Patient characteristics. A total of 13 patients with NSCLC developed CIP during immunotherapy between July 2016 and December 2018; 20 patients with NSCLC without CIP were included as controls. All patient baseline and treatment characteristics are presented in Table I. The age of the patients ranged between 36 and 82 years (mean, 66.8 years); the majority were Eastern Cooperative Oncology Group performance status (ECOG PS) (30) 0-1 $(n=22 ; 66.7 \%)$ and received single-agent anti-PD-1/PD-L1 therapy $(n=29 ; 87.9 \%)$. PD-1/PD-L1 antibodies included nivolumab (3 mg/kg; Bristol-Myers Squibb), pembrolizumab (2 mg/kg; Merck Sharp \& Dohme, Ltd.), atezolizumab (1,200 mg; Roche Diagnostics) and camrelizumab (200 mg; Jiangsu Hengrui Medicine Co., Ltd.). In total, 4 patients $(12.1 \%)$ received immunotherapy combined with chemotherapy. PD-L1 was detected in $14(58.3 \%)$ of the 24 patients for whom PD-L1 immunostaining (IHC 22C3 pharmDX, Agilent Technologies, Inc.) was available. None of the considered variables (age, sex, ECOG PS, smoking status, previous COPD, histological type, mutation status, PD-L1 expression, metastatic sites, type of immunotherapy regimen or previous treatment lines) were significantly different between the patients with CIP and the controls (Table I).

Clinical features of patients with CIP. Of the patients who developed CIP ( $n=13)$, pneumonitis occurred after a median of 3 cycles of immunotherapy (range, 1-6). The median time between initial immunotherapy and the onset of CIP was 49.8 days (range, $18-140$ days); 5 patients (38.5\%) initially presented with dyspnea, and $6(46.2 \%)$ with a cough, whereas 2 patients $(15.4 \%)$ were asymptomatic. Most of the patients exhibited grade $2-4$ pneumonitis $(11 / 13,84.6 \%)$, with the exception of 2 patients with grade $5(15.4 \%)$. In addition, 11 patients $(84.6 \%)$ with pneumonitis were treated with systemic steroids for a median of 24 days (range, 5-128 days). Of these patients, 4 completely recovered $(30.8 \%)$ and 7 improved $(53.8 \%)$, whereas 2 were admitted to the intensive care unit and succumbed to pneumonitis progression (15.4\%) (Table II).

Alterations in the serum levels of IL-17A and IL-35 are associated with CIP severity. The serum levels of IL-17A and IL-35 in the patients with CIP and controls during immunotherapy were longitudinally monitored within 2 weeks prior to IO treatment, at every two cycles of immunotherapy and upon onset of CIP. In patients with CIP ( $\mathrm{n}=13)$, median serum IL-17A levels increased significantly at the time of CIP diagnosis compared with baseline levels $(\mathrm{P}<0.001)$ and significantly decreased upon clinical recovery or improvement $(\mathrm{n}=11 ; \mathrm{P}=0.034)$ (Fig. 1A). In 2 CIP cases presenting with pneumonitis progression, the IL-17A level decreased upon administration of systemic steroids compared with CIP onset, but further increased at a later stage (Fig. 1E). Of note, the median serum levels of IL-35 displayed the same pattern as those of IL-17A (Fig. 1C and F). In the control patients with NSCLC who received ICI treatment $(n=20)$, the median serum levels of IL-17A and IL-35 increased slightly during immunotherapy compared with the baseline; however, no significant elevation in serum IL-17A or IL-35 levels was detected (Fig. 1B and D).

High frequencies of Th1 and Th17 cells are associated with the development of CIP. Next, the frequencies of different T-cell subsets were assessed by flow cytometry in 13 patients with CIP and 20 control subjects. As presented in Fig. 2, the percentages of Th17 and Th1 cells in patients with CIP were significantly higher following the onset of CIP compared 
Table I. Baseline characteristics of patients with NSCLC.

\begin{tabular}{|c|c|c|c|c|}
\hline Characteristics & Total $(n=33)$ & Patients with CIP $(n=13)$ & Control patients $(n=20)$ & $\mathrm{P}$-value \\
\hline Age, years & & & & 0.930 \\
\hline$\leq 65$ & 20 & 8 & 12 & \\
\hline$>65$ & 13 & 5 & 8 & \\
\hline Sex & & & & 0.801 \\
\hline Male & 22 & 9 & 13 & \\
\hline Female & 11 & 4 & 7 & \\
\hline ECOG PS & & & & 0.614 \\
\hline $0-1$ & 22 & 8 & 14 & \\
\hline 2 & 11 & 5 & 6 & \\
\hline Smoking status & & & & 0.960 \\
\hline Never & 3 & 1 & 2 & \\
\hline Present & 7 & 3 & 4 & \\
\hline History & 23 & 9 & 14 & \\
\hline Previous COPD & & & & 0.829 \\
\hline Yes & 16 & 6 & 10 & \\
\hline No & 17 & 7 & 10 & \\
\hline Histological type & & & & 0.619 \\
\hline Squamous & 16 & 7 & 9 & \\
\hline Non-squamous & 17 & 6 & 11 & \\
\hline Mutation status & & & & 0.343 \\
\hline EGFR & 4 & 2 & 2 & \\
\hline ALK & 0 & 0 & 0 & \\
\hline ROS1 & 0 & 0 & 0 & \\
\hline KRAS & 5 & 1 & 4 & \\
\hline Previous target therapy & & & & 0.906 \\
\hline Yes & 4 & 2 & 2 & \\
\hline No & 0 & 0 & 0 & \\
\hline PD-L1 expression (22C3) & & & & 0.534 \\
\hline$\leq 1 \%$ & 10 & 5 & 5 & \\
\hline$>1 \%$ & 14 & 4 & 10 & \\
\hline ND & 9 & 4 & 5 & \\
\hline Pathological stage & & & & 0.900 \\
\hline IIIB & 8 & 3 & 5 & \\
\hline IV & 25 & 10 & 15 & \\
\hline Metastatic sites, $n$ & & & & 0.663 \\
\hline $1-2$ & 24 & 10 & 14 & \\
\hline$\geq 3$ & 9 & 3 & 6 & \\
\hline Treatment line & & & & 0.338 \\
\hline $1 \mathrm{st}$ & 8 & 2 & 6 & \\
\hline$\geq 2$ nd & 25 & 11 & 14 & \\
\hline Immunotherapy & & & & 0.886 \\
\hline Nivolumab & 8 & 3 & 5 & \\
\hline Pembrolizumab & 10 & 5 & 5 & \\
\hline Atezolizumab & 6 & 2 & 4 & \\
\hline Camrelizumab & 5 & 1 & 4 & \\
\hline Pembro + Chemo & 4 & 2 & 2 & \\
\hline
\end{tabular}

${ }^{\mathrm{a}} \chi^{2}$ test. NSCLC, non-small cell lung cancer; CIP, checkpoint inhibitor pneumonitis; ECOG, Eastern Cooperative Oncology Group; PS, performance status; COPD, chronic obstructive pulmonary disease; EGFR, epidermal growth factor receptor; ALK, anaplastic lymphoma kinase; ROS1, ROS proto-oncogene 1; KRAS, KRAS proto-oncogene; PD-L1, programmed death receptor ligand 1; N, number; ND, no data; Pembro + Chemo, pembrolizumap + chemotherapy. 
Table II. Clinical features, treatment and outcome of CIP.

\begin{tabular}{lc}
\hline Variable & $\begin{array}{c}\text { Patients with } \\
\text { CIP }(\mathrm{n}=13)\end{array}$ \\
\hline Immunotherapy cycles, mean (range) & $3(1-6)$ \\
Time to CIP, days, mean (range) & $49.8(18-140)$ \\
Clinical symptoms, n (\%) & \\
Dyspnea & $5(38.5)$ \\
Cough & $6(46.2)$ \\
Asymptotic & $2(15.4)$ \\
Severity of CIP, $\mathrm{n}(\%)$ & \\
G2 & $2(15.4)$ \\
G3 & $5(38.5)$ \\
G4 & $4(30.8)$ \\
G5, & $2(15.4)$ \\
Steroid, $\mathrm{n}(\%)$ & $11(84.6)$ \\
Outcome, $\mathrm{n}(\%)$ & \\
Recovered & $4(30.8)$ \\
Improved & $7(53.8)$ \\
Succumbed & $2(15.4)$ \\
\hline
\end{tabular}

CIP, checkpoint inhibitor pneumonitis.

with those at baseline $(\mathrm{P}=0.014$ and $\mathrm{P}=0.029$; Fig. $2 \mathrm{~A}$ and $\mathrm{C}$, respectively), whereas no significant changes were detected in the control group (Fig. 2B and D). As a result, the ratios of Th17 to Tregs in patients with CIP (upon onset of CIP) were significantly higher compared with those at baseline $(\mathrm{P}=0.002$; Fig. 3A), and the ratios of Th1 to Th2 were significantly higher compared with those following improvement $(\mathrm{P}=0.042$; Fig. 3C). In the control group, the ratio of Th17 to Tregs in patients with NSCLC also increased following ICI treatment compared with that at baseline $(\mathrm{P}=0.441$; Fig. $3 \mathrm{~B})$; however, no increased ratios of $\mathrm{Th} 1$ to $\mathrm{Th} 2$ were observed in these patients (Fig. 3D). These results suggested that higher frequencies of Th1 and Th17 cells, as well as higher ratios of Th17 to Tregs and Th1 to Th 2 cells, may be associated with the development of CIP in patients with NSCLC.

Association between serum IL-17A and IL-35 levels and the percentages of different T-cell subsets in patients with NSCLC and CIP. To further clarify the roles of IL-17A and IL-35 in CIP, the correlation between the serum levels of these cytokines and the percentages of different T-cell subsets were investigated in patients with NSCLC and CIP (Fig. 4 for IL-17A and Fig. 5 for IL-35). The levels of serum IL-17A were positively correlated with the percentage of Th17 cells $(\mathrm{r}=0.537 ; \mathrm{P}=0.003$; Fig. 4D) and the ratio of Th17 to Tregs $(r=0.562 ; \mathrm{P}=0.001$; Fig. $4 \mathrm{~F})$. Serum IL-17A levels displayed no significant correlation with the frequency of Th1, Th2, Tregs or the ratio of Th1 to Th2 cells in patients with CIP $(r=0.343 ; \mathrm{P}=0.196$; Fig. 4A; $r=0.013$; $\mathrm{P}=1.000$; Fig. 4B; $\mathrm{r}=-0.350 ; \mathrm{P}=0.173$; Fig. 4E; and $\mathrm{r}=-0.024$; $\mathrm{P}=1.000$; Fig. 4C ). The levels of serum IL-35 were positively correlated with the percentages of Th1 $(\mathrm{r}=0.525 ; \mathrm{P}=0.004$; Fig. 5A) and the ratio of Th1 to Th2 cells ( $\mathrm{r}=0.479 ; \mathrm{P}=0.012$; Fig. 5C) in patients with CIP. However, no correlation was detected between serum IL-35 levels and frequency of Th2, Th17, Tregs or the ratio of Th17 to Treg cells in patients with CIP ( $\mathrm{r}=0.153 ; \mathrm{P}=1.000$; Fig. 5B; $\mathrm{r}=0.250 ; \mathrm{P}=0.746$; Fig. 5D; $\mathrm{r}=0.322 ; \mathrm{P}=0.273$; Fig. 5E; and $\mathrm{r}=0.195 ; \mathrm{P}=1.000$; Fig. $5 \mathrm{~F}$ ). These data suggested that the activation of Th1 and Th17 cells, as well as the inhibition of Tregs may contribute to the imbalanced ratio of Th1 to Th2 and Th17 to Tregs, thus leading to increased secretion of serum IL-17A and IL-35, and ultimately, the development of CIP.

Increased levels of IL-17A and IL-35 in the BALF and serum of patients with NSCLC and CIP. To further confirm the roles that IL-17A and IL-35 serve in the development of CIP, the levels of these cytokines were detected in the BALF of patients with CIP and the control patients during immunotherapy. In patients with CIP ( $n=9)$, BALF IL-17A levels increased significantly at the time of CIP diagnosis compared with baseline levels $(\mathrm{P}=0.010$; Fig. $6 \mathrm{~A})$, but no significant alteration was observed in the BALF of the control patients with NSCLC ( $n=10$; Fig. 6B). Levels of IL-35 in the BALF were also increased at the onset of CIP compared with those at the baseline ( $\mathrm{P}=0.008$; Fig. 6C). However, in 10 control patients with NSCLC who received ICI treatment, no significant elevation of IL-35 was detected in the BALF (Fig. 6D).

\section{Discussion}

Due to the wide spectrum of irAEs and the complexity of normal physiological interactions between the immune system and non-diseased tissues, the identification of biomarkers for irAEs is challenging. The underlying mechanism of CIP has not been fully elucidated; however, specific hyperactivation of the T-cell immune response and/or increased levels of inflammatory cytokines appear to be involved in the pathogenesis of irAEs (31). Largely on the basis of theory, current treatments of CIP include discontinuing medication, systemic corticosteroids and/or additional immune-suppressive medication, such as infliximab, mycophenolate mofetil, cyclophosphamide or intravenous immunoglobulins $(26-28,32)$. However, considering the complexity of CIP, the optimal guidelines for the management of CIP are still to be established.

IL-17A has been extensively studied as a crucial inflammatory cytokine, which is associated with autoimmune conditions $(33,34)$. Considering its essential role in mediating several acute and chronic respiratory pathologies, such as asthma (35) and idiopathic pulmonary fibrosis $(36,37)$, it may be hypothesized that IL-17A may participate in the autoimmune-pathological processes involved in CIP. In addition, as an inhibitory cytokine that can modulate activated $\mathrm{T}$ cells in immune dysfunctions, IL-35 has also been associated with pulmonary fibrosis, which is a characteristic pathogenic process of systemic sclerosis, a chronic systemic autoimmune disease $(22,38)$. However, although interstitial pneumonitis has been reported to be the most common pattern of CIP (19), which shares similar pathogenesis with pulmonary fibrosis, limited evidence exists to clarify the roles of IL-17A and IL-35 in the development of CIP.

In the present study, IL-17A and IL-35 were dynamically detected in a cohort of 13 patients with CIP and 20 controls 
A
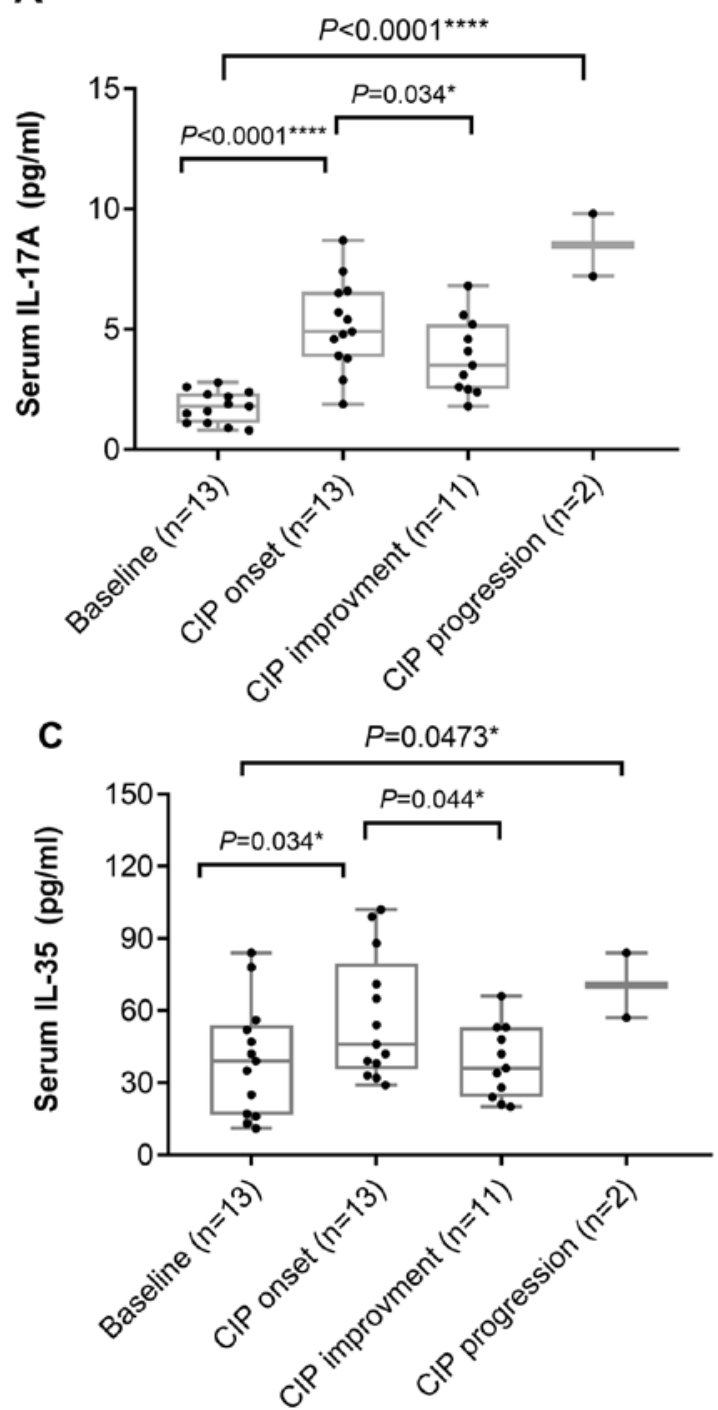

E

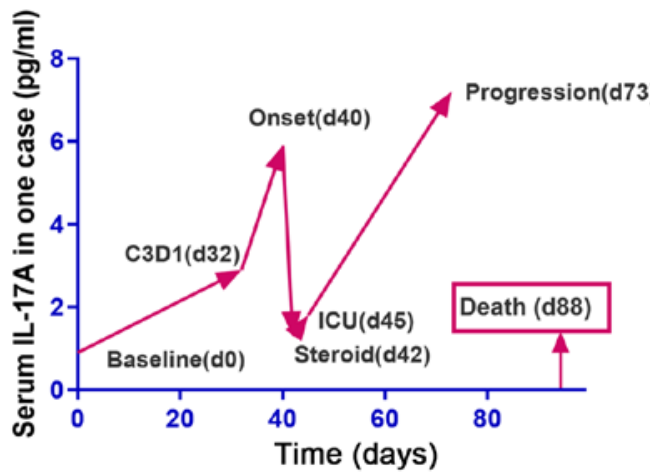

B
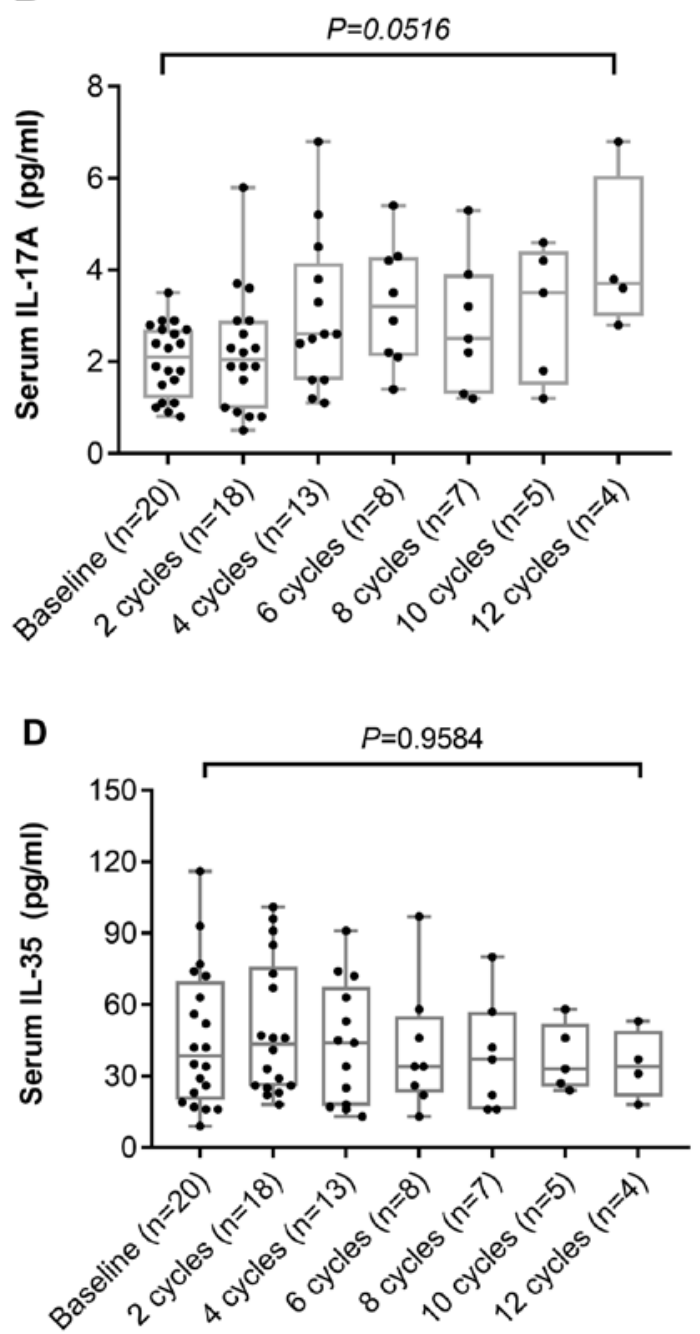

$\mathbf{F}$

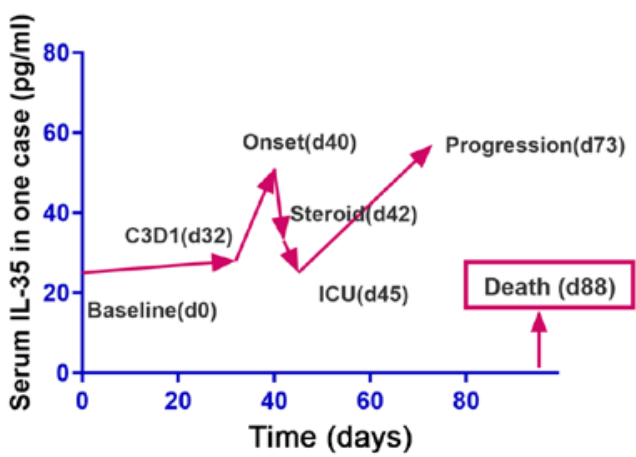

Figure 1. Alterations in serum levels of IL-17A and IL-35. (A and B) Serum IL-17A in (A) patients with CIP and (B) control patients. (C and D) Serum IL-35 in (C) patients with CIP and (D) controls. Kruskal-Wallis test was used for multiple comparisons. (E and F) Changes in the levels of (E) IL-17A and (F) IL-35 in one patient with severe CIP. IL, interleukin; CIP, checkpoint inhibitor pneumonitis; ICU, intensive care unit.

with NSCLC alone. The results indicated that serum levels of these cytokines significantly increased at the time of CIP diagnosis compared with the baseline, and decreased upon clinical recovery or improvement. In 2 CIP cases presenting with severe pneumonitis progression, markedly elevated levels of IL-17A and IL-35 were observed in the final stages of disease. Increased levels of IL-17A and IL-35 compared with baseline were also observed in the BALF of patients with CIP. PD-1/PD-L1 inhibitors disrupt immune tolerance, increasing the activation of T cells and immune responses (39). Therefore, the elevated levels of IL-17A in the plasma and the BALF may suggest a second wave of autoreactive $\mathrm{T}$ cells, which mediate not only tumor elimination, but also off-target pulmonary destruction in CIP. Notably, in NSCLC patients with CIP onset 
A

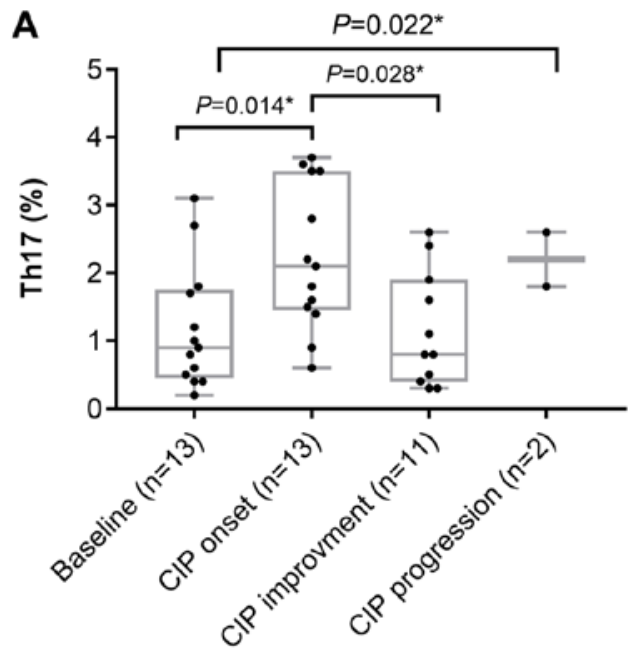

C

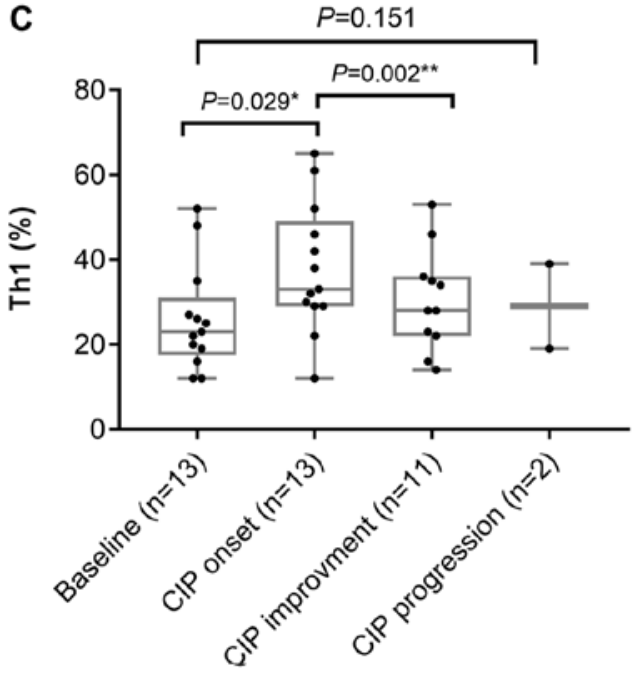

B

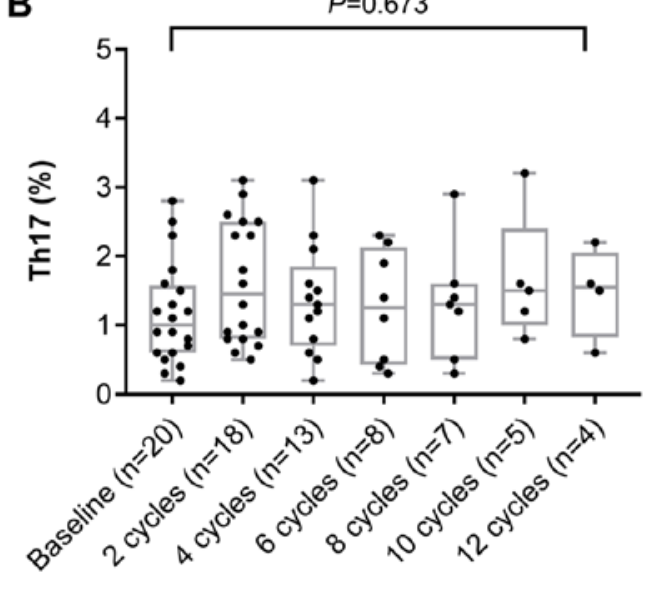

D

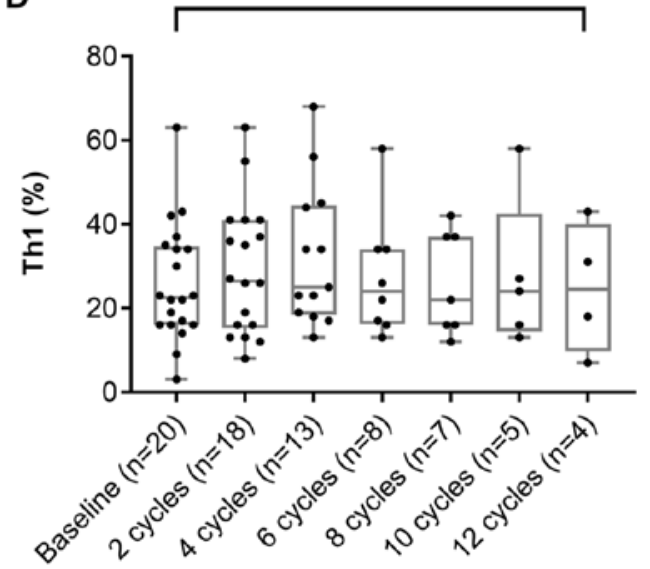

E

\section{는}

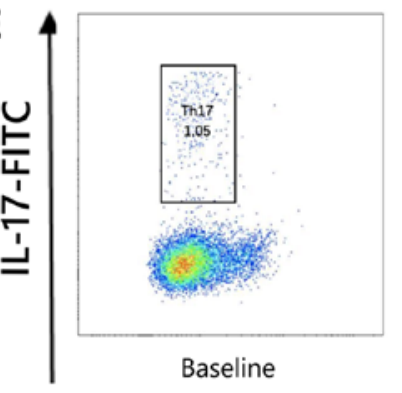

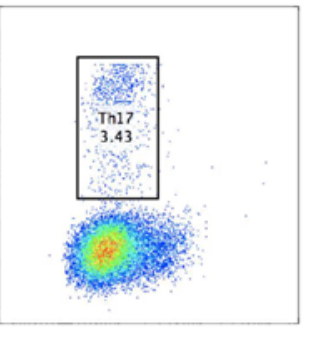

CIP onset

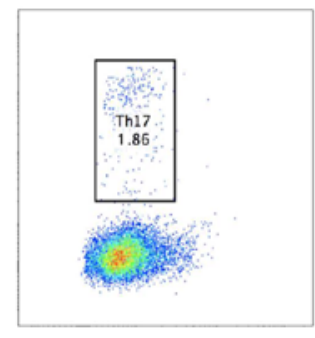

CIP improvement
$P=0.951$

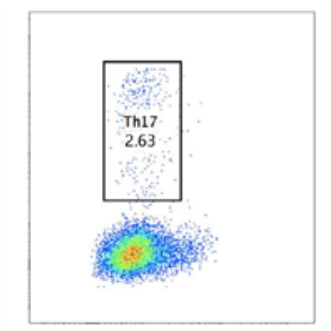

CIP progression

CD8-PE

\section{F}
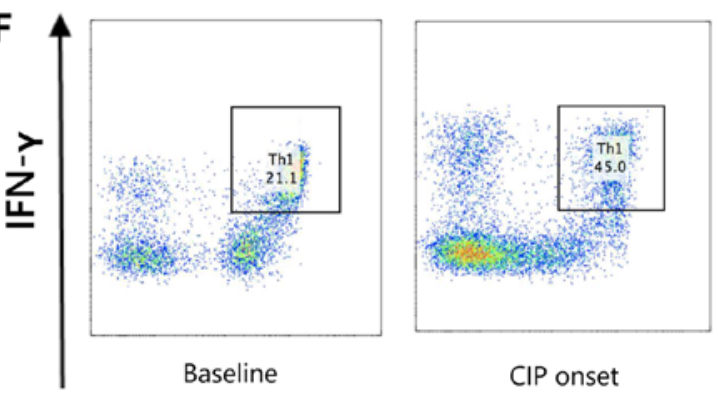

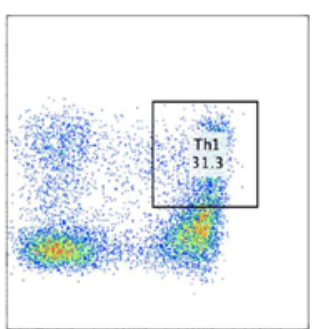

CIP improvement

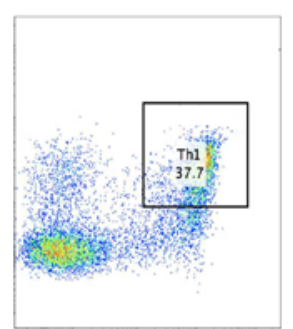

CIP progression

CD8-PE

Figure 2. Alterations in the percentage of Th1 and Th17. (A and B) Circulating Th17 percentage in (A) patients with CIP and (B) controls. (C and D) Circulating Th1 percentage in (C) patients with CIP and (D) controls. Kruskal-Wallis test was used for multiple comparisons. (E) Dot plots of the fluctuations in Th17 percentage in PBMCs from one representative patient with CIP. (F) Dot plots of the fluctuations in Th1 percentage in PBMCs from one representative patient with CIP. CIP, checkpoint inhibitor pneumonitis; Th, helper T lymphocyte; PBMCs, peripheral blood mononuclear cells; IL, interleukin; FITC, fluorescein isothiocyanate; IFN- $\gamma$, interferon- $\gamma$; PE, phycoerythrin. 
A

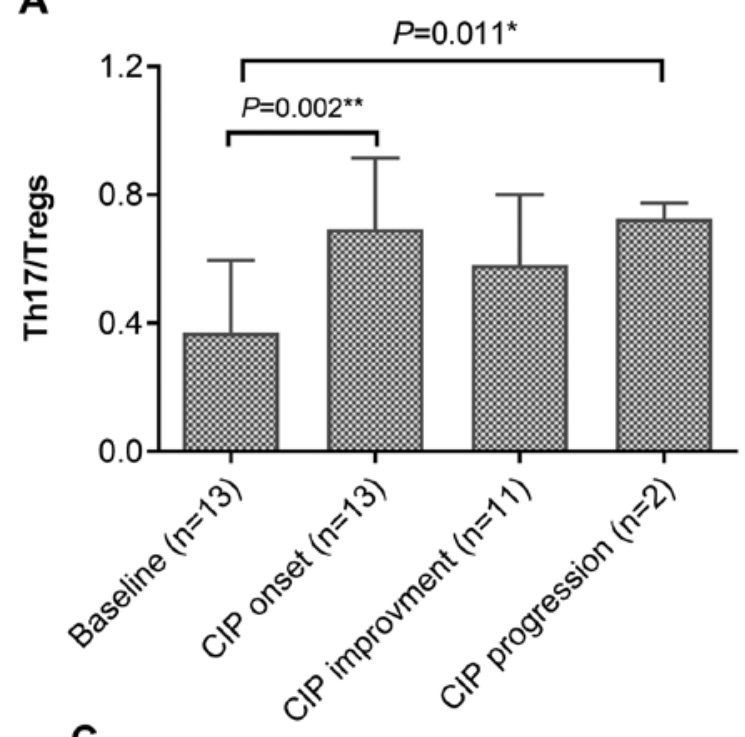

C

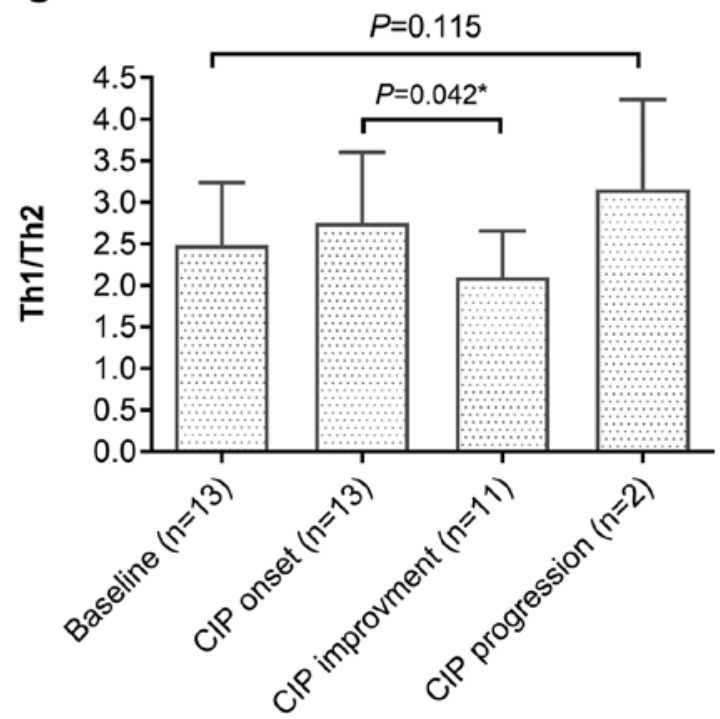

B

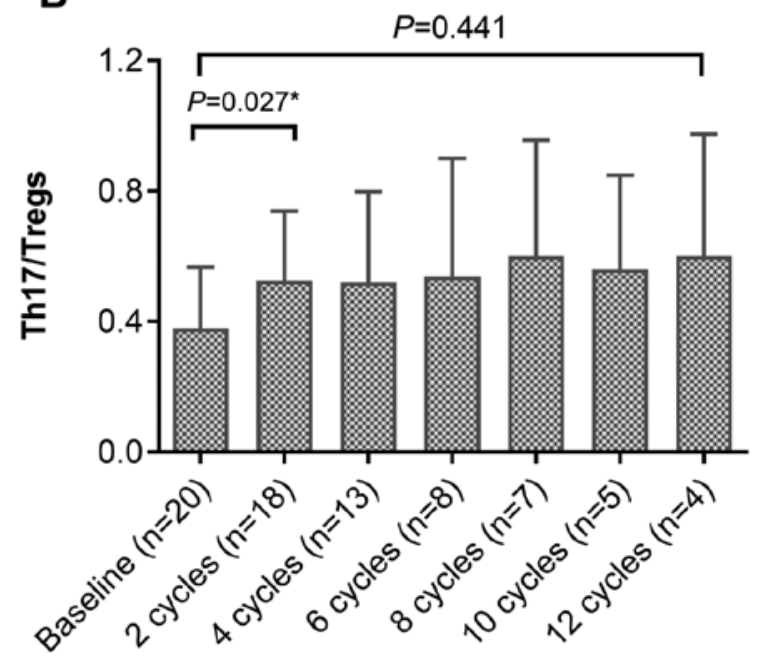

D

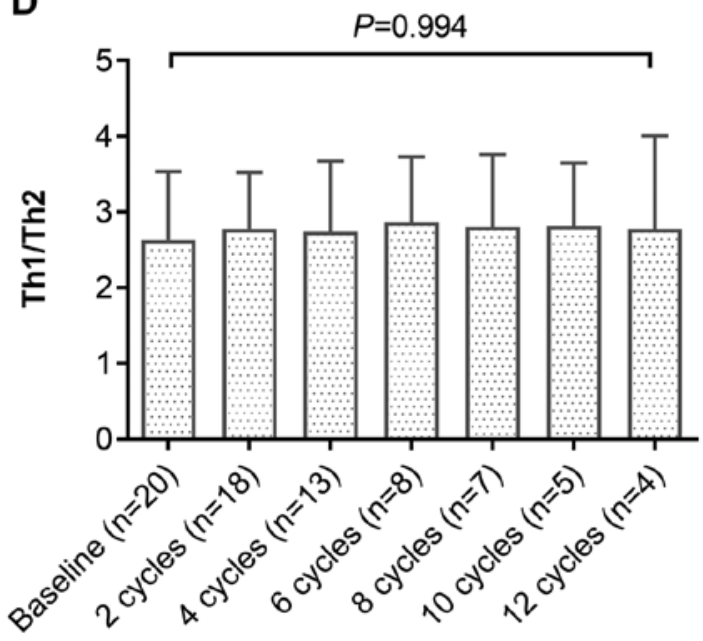

Figure 3. Alterations in the ratios of Th17 to Tregs and Th1 to Th2. (A and B) Ratio of Th17 to Tregs in (A) patients with CIP and (B) controls. (C and D) Ratio of Th1 to Th2 in (C) patients with CIP and (D) controls. Kruskal-Wallis test was used for multiple comparisons. CIP, checkpoint inhibitor pneumonitis; Th, helper T lymphocyte; Tregs, regulatory T cells.

during immunotherapy, increased levels of IL-35 seem to be insufficient to maintain immune tolerance or regulate reactive $\mathrm{T}$ cells for elevated levels of IL-17A were also observed. It is likely that the upregulation of IL-35 reflects a compensatory response to the PD-1/PD-L1 axis blockage, as well as an anti-inflammatory response to counteract IL-17A during the development of CIP. Functionally, both IL-17A and IL-35 have been reported to regulate pulmonary fibrosis $(40,41)$; thus, the aforementioned data support the cooperation of IL-35 and IL-17A in promoting CIP.

In the current study, different subtypes of $\mathrm{T}$ cells were dynamically detected, and a higher frequency of Th1 and Th17 cells, as well as higher ratios of Th17 to Tregs and Th1 to Th2, were associated with the development of CIP. In patients with NSCLC and CIP, the level of serum IL-17A was positively correlated with the percentage of Th17 cells and the ratio of Th17 to Tregs, and negatively associated with the frequency of Tregs. Concurrently, the levels of serum IL-35 were positively correlated with the percentage of Th1 and the ratio of Th1 to Th2 cells. These results support the notion that the activation of the IL-17/Th17 pathway is involved in the pathogenesis of CIP. In addition, Treg depletion promotes increased susceptibility of host cells to autoimmunity (42). Taken together, the activation of Th17 contributes to the imbalanced ratio of Th17 to Tregs, and ultimately results in the increased secretion of IL-17A. IL-17A then stimulates the secretion of tumor growth factor- $\beta 1$ (43), which induces IL-35 expression (40); together with the elevated levels of IL-17A, this in turn activates resting fibroblasts and contributes to the progression of autoimmune pneumonitis.

An enhanced Th1 response has been observed in the development of CIP during immunotherapy. The Th1 immune response is considered a key player in cell-mediated immunity (44), and Th1 dysfunction may promote cancer progression. A shift in the Th1 to Th2 ratio towards Th2 predominance indicates impairment of cell-mediated immunity, and is frequently 
A

$r=0.343, P=0.033^{*}$

Bonferroni's cor $P=0.196$

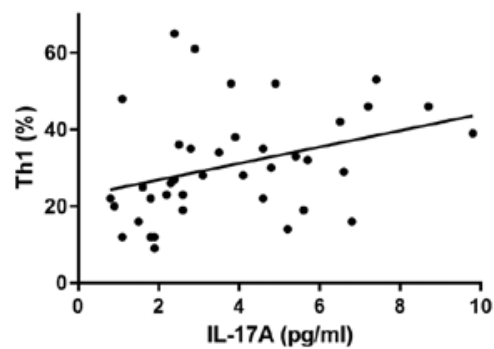

D $\quad r=0.537, P=0.0004^{\star * *}$

Bonferroni's cor $P=0.003^{* \star}$

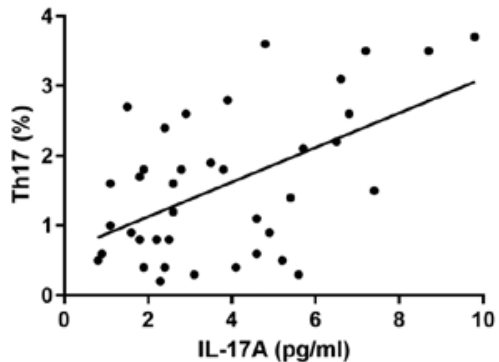

B

$r=0.013, P=0.939$

Bonferroni's cor $P=1.000$

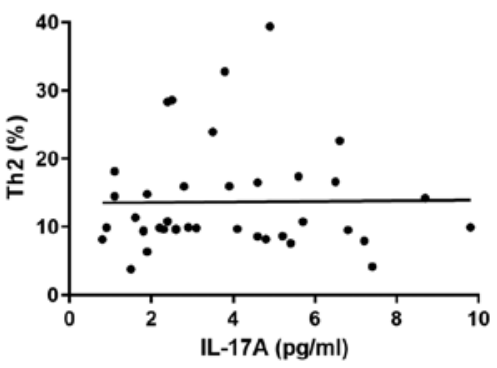

E

$r=-0.350, P=0.029^{*}$

Bonferroni's cor $P=0.173$

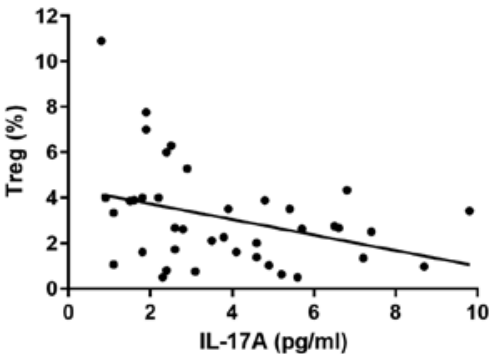

C

$r=-0.024, P=0.885$

Bonferroni's cor $P=1.000$

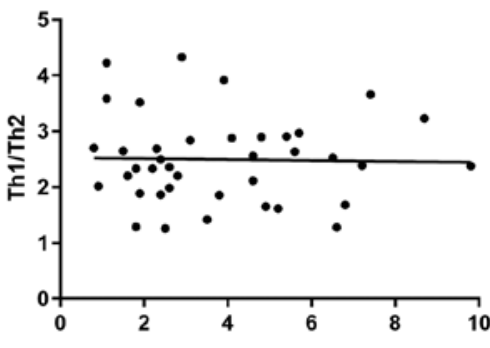

F $\quad r=0.562, P=0.0002^{\star * *}$

Bonferroni's cor $P=0.001^{* *}$

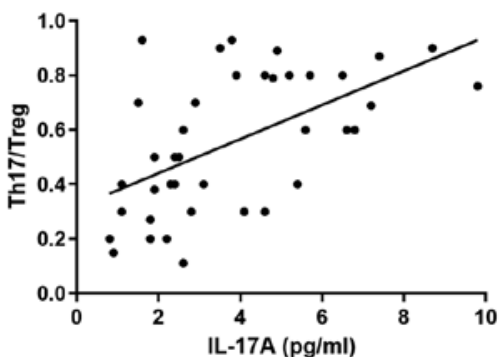

Figure 4. Correlations between serum levels of IL-17A and the percentages of different subsets of T cells in patients with CIP. (A, D and F) Positive correlation between IL-17A and (A) Th1, (D) Th17 and (F) Th17/Tregs. (B and C) No correlation was observed between IL-17A and (B) Th2 or (C) Th1/Th2. (E) Negative correlation between IL-17A and Tregs. Pearson correlation with Bonferroni correction used for correlation analysis. IL, interleukin; CIP, checkpoint inhibitor pneumonitis; Th, helper T lymphocyte; Tregs, regulatory T cells.
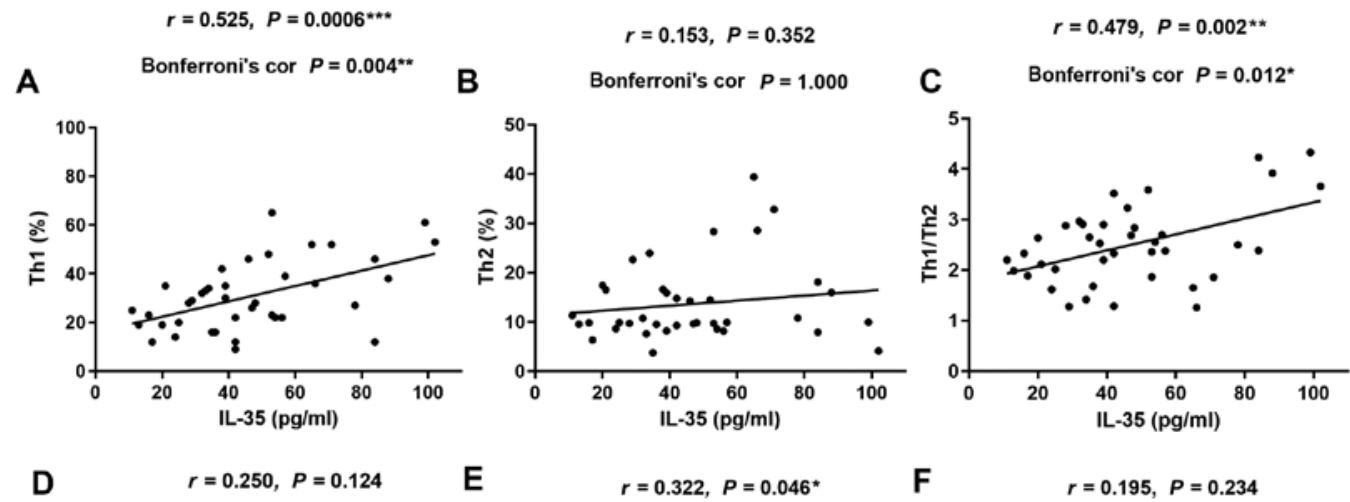

Bonferroni's cor $P=0.746$

E

$r=0.322, P=0.046^{*}$

$\mathbf{F}$

Bonferroni's cor $P=0.273$

$r=0.195, P=0.234$
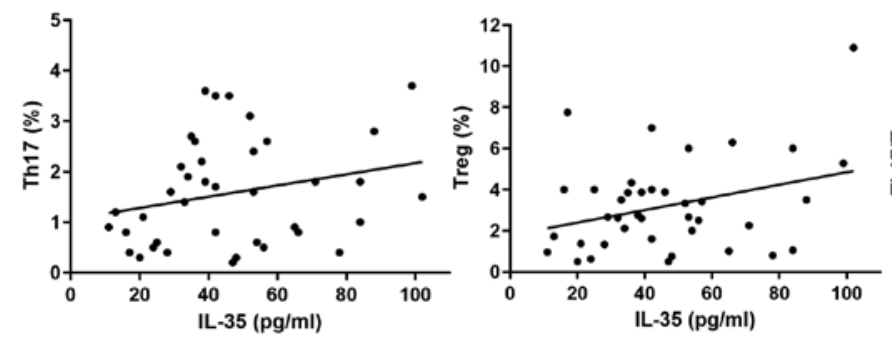

Bonferroni's cor $P=1.000$

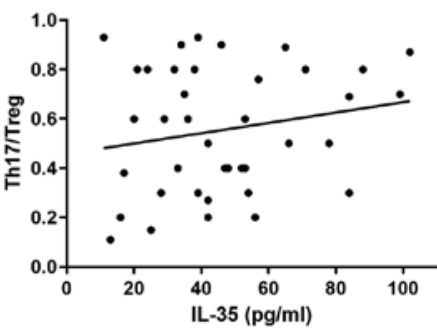

Figure 5. Correlations between serum levels of IL-35 and the percentages of different subsets of T cells in patients with CIP. (A, C and E) Positive correlation between IL-35 and (A) Th1, (C) Th1/Th2 and (E) Tregs. (B, D and F) No correlation was observed between IL-35 and (B) Th2, (D) Th17 or (F) Th17/Tregs. Pearson correlation with Bonferroni correction was used for correlation analysis. IL, interleukin; CIP, checkpoint inhibitor pneumonitis; Th, helper T lymphocyte; Tregs, regulatory T cells.

observed in the advanced stages of malignancy (45), while Th1 dominance is reportedly associated with high survival and low recurrence rates in patients with cancer (46). Therefore,
Th1 polarization in patients with CIP may trigger an excessive T-cell response, yet to some extent, it also implies a more effective defense against NSCLC. 
A
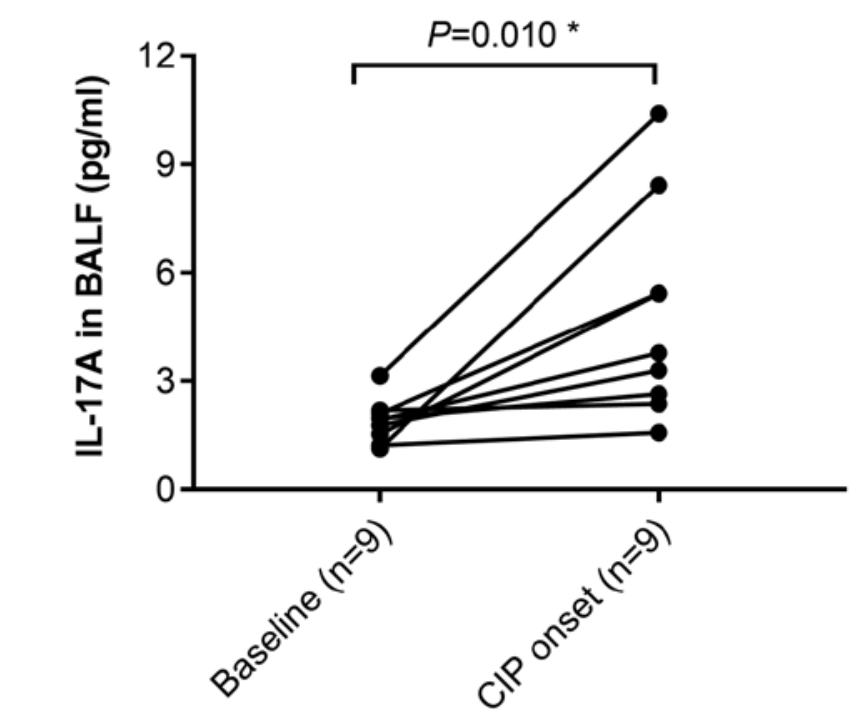

C

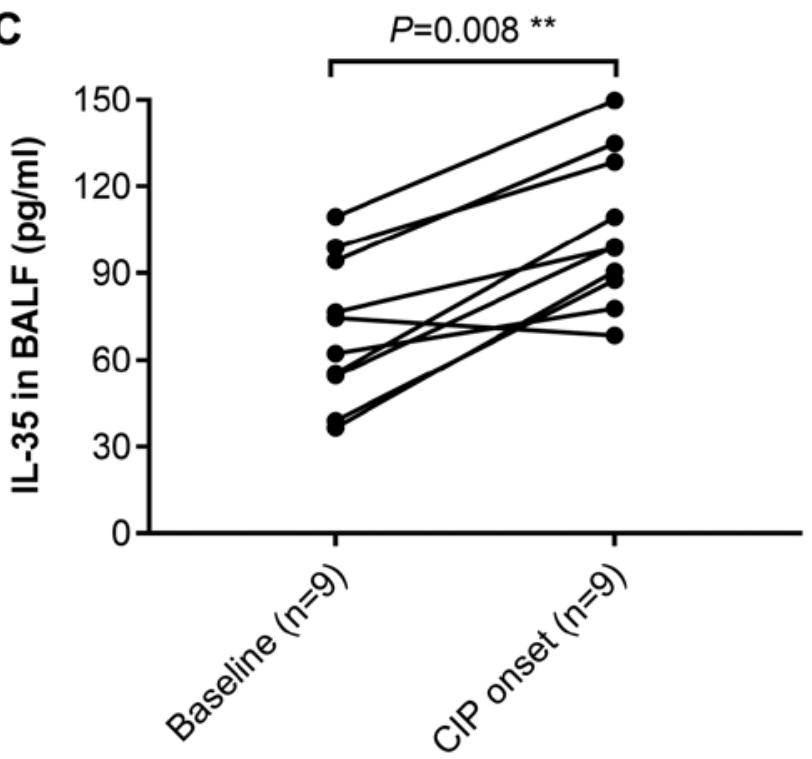

B
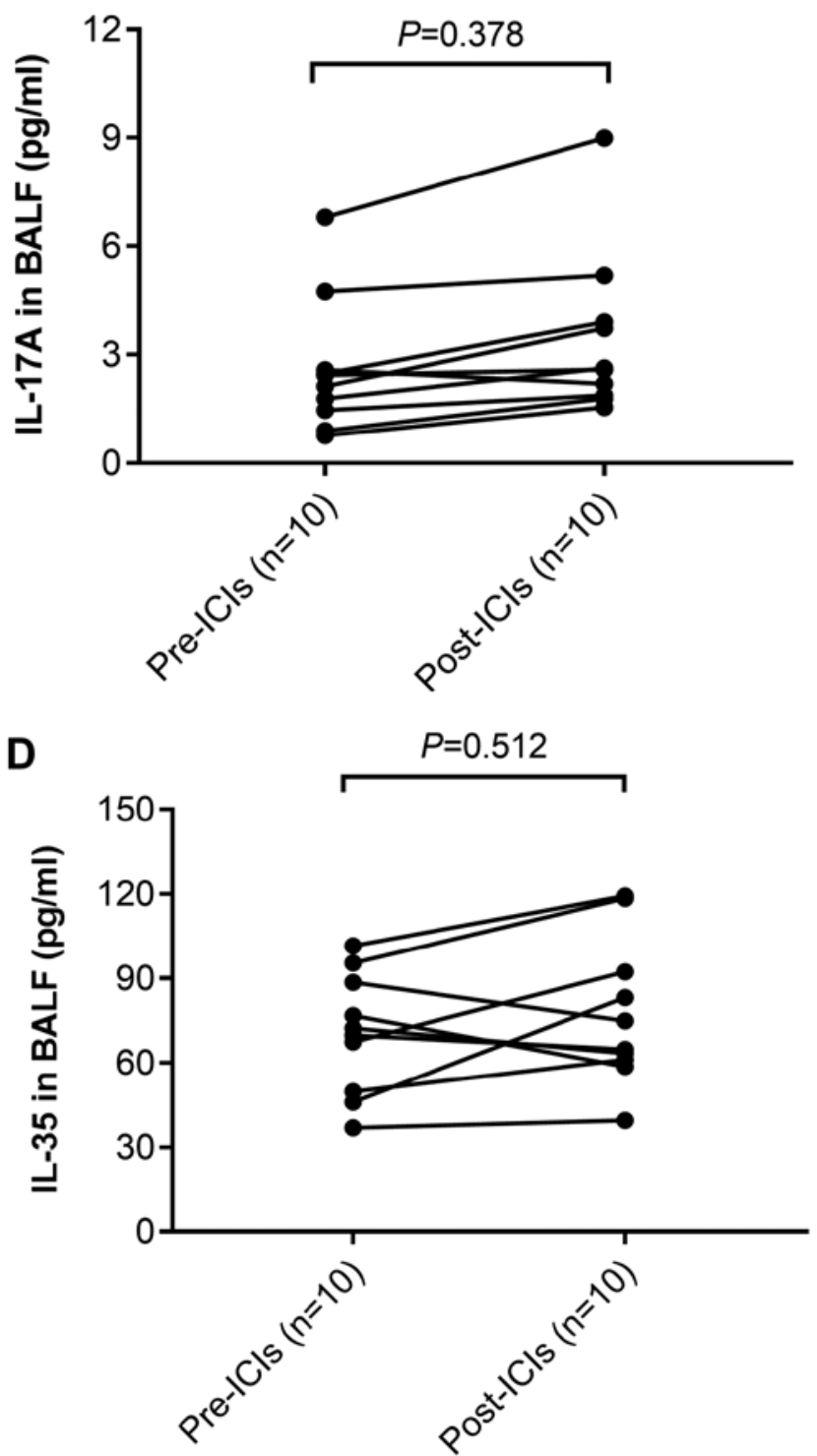

Figure 6. Alterations of IL-17A and IL-35 levels in BALF from patients with CIP and controls. (A and B) IL-17A levels in BALF of (A) patients with CIP and (B) controls. (C and D) IL-35 levels in BALF of (C) patients with CIP and (D) controls. IL, interleukin; CIP, checkpoint inhibitor pneumonitis; BALF, bronchoalveolar lavage fluid; ICI, immune checkpoint inhibitors.

In conclusion, the results of the current study indicate that significantly higher levels of IL-17A and IL-35 in the plasma and BALF are associated with the severity of pneumonitis. Furthermore, the level of serum IL-17A was positively correlated with Th1 and Th17 percentages, and the ratio of Th17 to Tregs, whereas that of IL-35 was positively associated with the percentage of Th1 and Tregs, and the ratio of Th1 to Th2 cells in patients with CIP. Thus, IL-17A, together with IL-35, may contribute to the pathogenesis of pulmonary fibrosis during the development of CIP. The levels of IL-17A and IL-35 may be effective indicators of not only the development, but also the severity of pulmonary impairment in CIP. Notably, due to the relatively low incidence of CIP, these analyses focused on PD-1/PD-L1 antibody-related pneumonitis, and thus included a limited number of subjects. Further investigation is required to confirm these results and to determine more appropriate biomarkers for predicting the risk of this rare, but fatal adverse effect. Additional research will also improve our understanding of such regulatory systems and may yield insights for more effective therapeutic approaches to irAEs.

\section{Acknowledgements}

The authors are grateful to Dr Wei Wu from State Key Laboratory of Infectious Disease Diagnosis and Treatment, First Affiliated Hospital, Zhejiang University School of Medicine, for assistance with manuscript preparation and literature searches.

\section{Funding}

This study was funded by grants from Zhejiang Provincial Natural Science Foundation of China (grant no. LY16H160006) 
and Hangzhou Science and Technology Bureau (grant no. 20160533 B72).

\section{Availability of data and materials}

The datasets used and/or analyzed during the current study are available from the corresponding author on reasonable request.

\section{Authors' contributions}

HC conceived and designed the study. YW and DFL also helped design the study. WJ and WG performed the experiments and collected the data. DYL and JD analyzed and interpreted the data. YW and DFL wrote the manuscript and revised it for important intellectual content. All authors read and approved the final manuscript.

\section{Ethics approval and consent to participate}

Human samples were provided by the Department of Medical Oncology, The First Affiliated Hospital, Zhejiang University School of Medicine, following approval by the Institutional Review Board of the Cancer Research Institute. Written informed consent was obtained from all patients.

\section{Patient consent for publication}

Not applicable.

\section{Competing interests}

The authors declare that they have no competing interests.

\section{References}

1. Peters S, Kerr KM and Stahel R: PD-1 blockade in advanced NSCLC: A focus on pembrolizumab. Cancer Treat Rev 62 39-49, 2018.

2. Gentzler R, Hall R, Kunk PR, Gaughan E, Dillon P, Slingluff CL Jr and Rahma OE: Beyond melanoma: Inhibiting the PD-1/PD-L1 pathway in solid tumors. Immunotherapy 8: 583-600, 2016.

3. Massari F, Santoni M, Ciccarese C, Santini D, Alfieri S, Martignoni G, Brunelli M, Piva F, Berardi R, Montironi R, et al: PD-1 blockade therapy in renal cell carcinoma: Current studies and future promises. Cancer Treat Rev 41: 114-121, 2015.

4. Wang Y, Wu L, Tian C and Zhang Y: PD-1-PD-L1 immune-checkpoint blockade in malignant lymphomas. Ann Hematol 97: 229-237, 2018.

5. Zhou TC, Sankin AI, Porcelli SA, Perlin DS, Schoenberg MP and Zang X: A review of the PD-1/PD-L1 checkpoint in bladder cancer: From mediator of immune escape to target for treatment. Urol Oncol 35: 14-20, 2017.

6. Johnson DB, Chandra S and Sosman JA: Immune checkpoint inhibitor toxicity in 2018. JAMA 320: 1702-1703, 2018.

7. Topalian SL, Hodi FS, Brahmer JR, Gettinger SN, Smith DC, McDermott DF, Powderly JD, Carvajal RD, Sosman JA Atkins MB, et al: Safety, activity, and immune correlates of anti-PD-1 antibody in cancer. N Engl J Med 366: 2443-2454, 2012.

8. Balaji A, Verde F, Suresh K and Naidoo J: Pneumonitis from anti-PD-1/PD-L1 therapy. Oncology (Williston Park) 31: 739-746, 2017

9. Ribas A, Puzanov I, Dummer R, Schadendorf D, Hamid O, Robert C, Hodi FS, Schachter J, Pavlick AC, Lewis KD, et al: Pembrolizumab versus investigatorchoice chemotherapy for ipilimumab-refractory melanoma (KEYNOTE-002): A randomised, controlled, phase 2 trial. Lancet Oncol 16: 908-918, 2015.
10. Hamid O, Robert C, Daud A, Hodi FS, Hwu WJ, Kefford R, Wolchok JD, Hersey P, Joseph RW, Weber JS, et al: Safety and tumor responses with lambrolizumab (anti-PD-1) in melanoma. N Engl J Med 369: 134-144, 2013.

11. Borghaei H, Paz-Ares L, Horn L, Spigel DR, Steins M, Ready NE, Chow LQ, Vokes EE, Felip E, Holgado E, et al: Nivolumab versus docetaxel in advanced nonsquamous non-small-cell lung cancer. N Engl J Med 373: 1627-1639, 2015.

12. Brahmer J, Reckamp KL, Baas P, Crinò L, Eberhardt WE, Poddubskaya E, Antonia S, Pluzanski A, Vokes EE, Holgado E, et al: Nivolumab versus docetaxel in advanced squamous-cell non-small-cell lung cancer. N Engl J Med 373: 123-135, 2015.

13. Herbst RS, Baas P, Kim DW, Felip E, Pérez-Gracia JL, Han JY, Molina J, Kim JH, Arvis CD, Ahn MJ, et al: Pembrolizumab versus docetaxel for previously treated,PD-L1-positive, advanced nonsmall-cell lung cancer (KEYNOTE-010): A randomised controlled trial. Lancet 387: 1540-1550, 2016.

14. Robert C, Long GV, Brady B, Dutriaux C, Maio M, Mortier L, Hassel JC, Rutkowski P, McNeil C, Kalinka-Warzocha E, et al: Nivolumab in previously untreated melanoma without BRAF mutation. N Engl J Med 372: 320-330, 2015.

15. Robert C, Schachter J, Long GV, Arance A, Grob JJ, Mortier L, Daud A, Carlino MS, McNeil C, Lotem M, et al: Pembrolizumab versus ipilimumab in advanced melanoma. N Engl J Med 372: 2521-2532, 2015.

16. Weber JS, D'Angelo SP, Minor D, Hodi FS, Gutzmer R, Neyns B, Hoeller C, Khushalani NI, Miller WH Jr, Lao CD, et al: Nivolumab versus chemotherapy in patients with advanced melanoma who progressed after anti-CTLA-4 treatment (CheckMate 037): A randomised, controlled, open-label, phase 3 trial. Lancet Oncol 16: 375-384, 2015.

17. Pardoll DM: The blockade of immune checkpoints in cancer immunotherapy. Nat Rev Cancer 12: 252-264, 2012.

18. Barjaktarevic IZ, Qadir N, Suri A, Santamauro JT and Stover D: Organizing pneumonia as a side effect of ipilimumab treatment of melanoma. Chest 143: 858-861, 2013.

19. Naidoo J, Wang X, Woo KM, Iyriboz T, Halpenny D, Cunningham J, Chaft JE, Segal NH, Callahan MK, Lesokhin AM, et al: Pneumonitis in patients treated with antiprogrammed death-1/programmed death ligand 1 therapy. J Clin Oncol 35: 709-717, 2017

20. Iwanaga $\mathrm{N}$ and Kolls JK: Updates on $\mathrm{T}$ helper type 17 immunity in respiratory disease. Immunology 156: 3-8, 2019

21. Collison LW, Workman CJ, Kuo TT, Boyd K, Wang Y, Vignali KM, Cross R, Sehy D, Blumberg RS and Vignali DA: The inhibitory cytokine IL-35 contributes to regulatory T-cell function. Nature 450: 566-569, 2007

22. Tang J, Lei L, Pan J, Zhao C and Wen J: Higher levels of serum interleukin-35 are associated with the severity of pulmonary fibrosis and $\mathrm{Th} 2$ responses in patients with systemic sclerosis. Rheumatol Int 38: 1511-1519, 2018

23. Konishi J, Yamazaki K, Kinoshita I, Isobe H, Ogura S, Sekine S, Ishida T, Takashima R, Nakadate M, Nishikawa S, et al: Analysis of the response and toxicity to gefitinib of non-small cell lung cancer. Anticancer Res 25: 435-441, 2005.

24. Grande C, Villanueva MJ, Huidobro G and Casal J: Docetaxelinduced interstitial pneumonitis following non-small-cell lung cancer treatment. Clin Transl Oncol 9: 578-581, 2007.

25. Delaunay M, Cadranel J, Lusque A, Meyer N, Gounant V, Moro-Sibilot D, Michot JM, Raimbourg J, Girard N, Guisier F, et al: Immune-checkpoint inhibitors associated with interstitial lung disease in cancer patients. Eur Respir J 50: $1700050,2017$.

26. Brahmer JR, Lacchetti C, Schneider BJ, Atkins MB, Brassil KJ, Caterino JM, Chau I, Ernstoff MS, Gardner JM, Ginex P, et al: National comprehensive cancer network. Management of immune-related adverse events in patients treated with immune checkpoint inhibitor therapy: American society of clinical oncology clinical practice guideline. J Clin Oncol 36: 1714-1768, 2018.

27. Haanen JBAG, Carbonnel F, Robert C, Kerr KM, Peters S, Larkin J, Jordan K and ESMO Guidelines Committee: Management of toxicities from immunotherapy: ESMO clinical practice guidelines for diagnosis, treatment and follow-up. Ann Oncol 29 (Suppl 4): iv264-iv266, 2018.

28. Puzanov I, Diab A, Abdallah K, Bingham CO III, Brogdon C, Dadu R, Hamad L, Kim S, Lacouture ME, LeBoeuf NR, et al: Society for immunotherapy of cancer toxicity management working group. Managing toxicities associated with immune checkpoint inhibitors: Consensus recommendations from the society for immunotherapy of cancer (SITC) toxicity management working group. J Immunother Cancer 5: 95, 2017. 
29. US Department of Health and Human Services, National Institutes of Health, National Cancer Institute: Common Terminology Criteria for Adverse Events (CTCAE) Version 4.0. https://evs.nci.nih.gov/ftp1/CTCAE/CTCAE_4.03/Archive/ CTCAE_4.0_2009-05-29_QuickReference_8.5x11.pdf. Accessed May 28, 2009.

30. Oken MM, Creech RH, Tormey DC, Horton J, Davis TE, McFadden ET and Carbone PP: Toxicity and response criteria of the eastern cooperative oncology group. Am J Clin Oncol 5: 649-655, 1982.

31. Postow MA, Sidlow R and Hellmann MD: Immune-related adverse events associated with immune checkpoint blockade. N Engl J Med 378: 158-168, 2018.

32. Friedman CF, Proverbs-Singh TA and Postow MA: Treatment of the immune-related adverse effects of immune checkpoint inhibitors: A review. JAMA Oncol 2: 1346-1353, 2016.

33. Park H, Li Z, Yang XO, Chang SH, Nurieva R, Wang YH, Wang Y, Hood L, Zhu Z, Tian Q and Dong C: A distinct lineage of CD4 T cells regulates tissue inflammation by producing interleukin 17. Nat Immunol 6: 1133-1141, 2005.

34. Miossec P and Kolls JK: Targeting IL-17 and TH17 cells in chronic inflammation. Nat Rev Drug Discov 11: 763-376, 2012

35. Cosmi L, Liotta F and Annunziato F: Th17 regulating lower airway disease. Curr Opin Allergy Clin Immunol 16: 1-6, 2016.

36. Wilson MS, Madala SK, Ramalingam TR, Gochuico BR, Rosas IO, Cheever AW and Wynn TA: Bleomycin and IL-1beta-mediated pulmonary fibrosis is IL-17A dependent. J Exp Med 207: 535-552, 2010.

37. Zhang J, Wang D, Wang L, Wang S, Roden AC, Zhao H, Li X, Prakash YS, Matteson EL, Tschumperlin DJ and Vassallo R: Profibrotic effect of IL-17A and elevated IL-17RA in idiopathic pulmonary fibrosis and rheumatoid arthritis-associated lung disease support a direct role for IL-17A/IL-17RA in human fibrotic interstitial lung disease. Am J Physiol Lung Cell Mol Physiol 316: L487-L497, 2019.

38. Dantas AT, Gonçalves SM, Pereira MC, Gonçalves RS, Marques CD, Rego MJ, Pitta Ida R, Duarte AL and Pitta MG: Increased IL-35 serum levels in systemic sclerosis and association with pulmonary interstitial involvement. Clin Rheumatol 34: $1621-1625,2015$
39. Makkouk A and Weiner GJ: Cancer immunotherapy and breaking immune tolerance: New approaches to an old challenge. Cancer Res 75: 5-10, 2015.

40. Galati D, De Martino M, Trotta A, Rea G, Bruzzese D, Cicchitto G, Stanziola AA, Napolitano M, Sanduzzi A and Bocchino M: Peripheral depletion of NK cells and imbalance of the Treg/Th17 axis in idiopathic pulmonary fibrosis patients. Cytokine 66: 119-126, 2014

41. Tomcik M, Zerr P, Palumbo-Zerr K, Storkanova H, Hulejova H, Spiritovic M, Kodet O, Stork J, Becvar R, Vencovsky J, et al: Interleukin-35 is upregulated in systemic sclerosis and its serum levels are associated with early disease. Rheumatology (Oxford) 54: 2273-2282, 2015.

42. Tanaka A and Sakaguchi S: Regulatory T cells in cancer immunotherapy. Cell Res 27: 109-118, 2017.

43. Mi S, Li Z, Yang HZ, Liu H, Wang JP, Ma YG, Wang XX, Liu HZ Sun $\mathrm{W}$ and Hu ZW: Blocking IL-17A promotes the resolution of pulmonary inflammation and fibrosis via TGF-beta1-dependent and -independent mechanisms. J Immunol 187: 3003-3014, 2011.

44. Kaiko GE, Horvat JC, Beagley $\mathrm{KW}$ and Hansbro PM: Immunological decision making: How does the immune system decide to mount a helper T-cell response? Immunology 123: 326-338, 2008

45. Munn DH: Blocking IDO activity to enhance anti-tumor immunity. Front Biosci (Elite Ed) 4: 734-745, 2012.

46. Tosolini M, Kirilovsky A, Mlecnik B, Fredriksen T, Mauger S, Bindea $G$, Berger A, Bruneval P, Fridman WH, Pagès F and Galon J: Clinical impact of different classes of infiltrating T cytotoxic and helper cells (Th1, th2, treg, th17) in patients with colorectal cancer. Cancer Res 71: 1263-1271, 2011. International (CC BY-NC-ND 4.0) License. 